\title{
Idiopathic Thrombocytopenic Purpura Related to COVID-19
}

\author{
Mariana M. Langhi ${ }^{\mathrm{a}}$, Andre N.R. Abdo ${ }^{\mathrm{a}}$, , Juliana F.B. Putz ${ }^{\mathrm{a}}$, Lizandra M. Carvalho ${ }^{\mathrm{a}}$, \\ Silvia R. Loss ${ }^{\mathrm{a}}$, Jose P. Zampieri Filho ${ }^{\mathrm{a}}$, Jose O. Bordinn ${ }^{\mathrm{a}}$, Phillip Bachour ${ }^{\mathrm{a}}$, \\ Otavio C.C.G. Baiocchi ${ }^{\mathrm{a}}$
}

\begin{abstract}
Since December 2019, a newly identified coronavirus disease 2019 (COVID-19) has spread in China and the rest of world. There are many doubts regarding pathogenesis as well complications due to COVID-19. We report a case with association between thrombocytopenia and the new severe acute respiratory syndrome coronavirus 2 (SARS-CoV-2) infection after exclusion of other possible etiology in a patient with previous controlled idiopathic thrombocytopenic purpura.
\end{abstract}

Keywords: COVID-19; ITP; Thrombocytopenia

\section{Introduction}

Idiopathic thrombocytopenic purpura (ITP) is a common autoimmune disorder characterized by accelerated immune-mediated destruction of platelets [1]. The etiology of ITP is still unknown, and the diagnosis remains exclusionary. In $80 \%$ of the cases it may present alone (primary) or with other associated (secondary) clinical conditions, such as viral and bacterial infections or changes in immune status [2,3]. Identifying trigger factors that cause ITP is extremely difficult, and a variety of viral infections have been associated with ITP, among which the most common ones are the human immunodeficiency virus (HIV), hepatitis $\mathrm{C}$ virus and hepatitis $\mathrm{B}$ virus. In this context, no data regarding infection of the SARS-CoV-2 and exacerbation of previous ITP treated with splenectomy have been recently published.

Here, we present a clinical case of exacerbation of ITP related to COVID-19, a disease whose causative agent is a virus of Coronaviridae family, and a producer of respiratory and systemic disease, which could progress to a severe form of pneumonia in $10-15 \%$ of patients [4].

Manuscript submitted June 2, 2020, accepted June 11, 2020

Published online June 29, 2020

a Oncology Center at Hospital Alemao Oswaldo Cruz, Sao Paulo, Brazil ${ }^{b}$ Corresponding Author: Andre N. R. Abdo, Oncology Center at Hospital Alemao Oswaldo Cruz, Sao Paulo, Brazil. Email: andre.abdo@hc.fm.usp.br

doi: https://doi.org/10.14740/jmc3518

\section{Case Report}

A 46-year-old man diagnosed with ITP since childhood and submitted to splenectomy at age of 9 years, had stabilized platelet levels between around $50,000 / \mathrm{mm}^{3}$ without any further treatment. Recently, in March 2020 the patient presented with a history of odynophagia, headache, and fever with dry cough for a couple of days. At this time, no shortness of breath was documented. On physical examination, lungs were clear and respiratory frequency was normal. Petechiae throughout lower limbs were found.

Initial laboratory showed platelets of $9,000 / \mathrm{mm}^{3}$ and Ddimer of 630 (normal range up to $500 \mathrm{ng} / \mathrm{mL}$ ), with no other tests abnormalities. The identification of SARS-CoV-2 by reverse transcription polymerase chain reaction (RT-PCR) from nasopharynx swab was positive while other viral studies (influenza, parainfluenza and dengue virus) were negative. Chest tomography revealed incipient peribronchovascular micronodular opacities in the periphery of the lower lobe of the left lung, suggesting a tenuous inflammatory/infectious process. Despite the previous history of ITP, new tests for HIV, hepatitis $\mathrm{C}$ and $\mathrm{B}$ were done and came negative. Bone marrow aspirate showed normocellular with no morphological changes. In order to avoid high dose corticosteroids, we started treatment with a single course of intravenous human immunoglobulin 1 $\mathrm{g} / \mathrm{kg}$ and eltrombopag $50 \mathrm{mg}$ daily. No antimicrobial treatment or any other therapy for COVID-19 was given.

After 3 days of treatment, platelets levels increased to $36,000 / \mathrm{m}^{3}$ and the patient was discharged from the hospital in very good health condition, without fever or cough. Fifteen days after discharge, no SARS-CoV-2 viral load was detected and platelets count was $320,000 / \mathrm{mm}^{3}$.

\section{Discussion}

The relationship between acute and chronic infections and the development of immune-mediated thrombocytopenia represent a widely unexplored paradigm, and response to an infectious agent could result in loss of immune self-regulation. The pathophysiology of thrombocytopenic purpura with infection involves several immunological pathways, as well as non-immune mechanisms that accelerate platelet destruction.

Noteworthy, during infections other potential causes of thrombocytopenia should always be considered, for example, 
hepatitis $\mathrm{C}$-associated thrombocytopenia (HCV) may also result from liver cirrhosis, leading to portal hypertension and hypersplenism and/or decreased liver production of thrombopoietin [5]. However, the relationship between the infectious agent and the development of thrombocytopenia is clearly demonstrated by improvements in platelet levels following successful treatment of the underlying infection $[6,7]$.

Regarding acute infections, it has long been suspected that an acute event may be a trigger for the onset of primary ITP. In newly diagnosed ITP, there is usually a history of symptoms that can be attributed to infection in the days or weeks before diagnosis. In some cases, a pathogen is detected (e.g., Epstein-Barr virus (EBV), influenza virus, varicella-zoster virus), which qualifies these cases as secondary ITP. However, in most acute cases of ITP, a pathogen is not identified [8].

SARS-CoV-2 was identified in late 2019 as the cause of a set of pneumonia cases in Wuhan, China. Since then, it has spread rapidly, resulting in a pandemic crisis. Morbidity and mortality of COVID-19 are largely due to acute viral pneumonitis that could progresses to acute respiratory distress syndrome (ARDS), however most patients are oligosymptomatic or asymptomatic [9].

Several newly published articles relate platelet count and acute infection by the new corona virus [10-13]. Recently, a Chinese meta-analysis associated thrombocytopenia with severe infection by the new coronavirus. This meta-analysis demonstrated that thrombocytopenia is common in critically ill patients and usually suggests malfunction or physiological decompensation, as well as the development of intravascular coagulopathy, often evolving to disseminated intravascular coagulation (DIC). In patients with COVID-19, the mechanism for patients with thrombocytopenia is likely to be multifactorial. In SARS, it was suggested that the combination of viral infection and mechanical ventilation would lead to endothelial damage, triggering platelet activation, aggregation and thrombosis in the lung, causing widespread platelet consumption. Coronavirus can also directly infect bone marrow elements, resulting in abnormal hematopoiesis or trigger an autoimmune response against blood cells [14].

In another publication with 47 cases of COVID-19 infection in Saudi Arabia, leukopenia (14\%), lymphopenia (34\%), lymphocytosis (11\%) and thrombocytopenia (36\%) were reported [15]. In our case, the patient had a previous diagnosis of ITP treated with splenectomy, and although with very low platelets, no signs of clinical severity related to the new coronavirus were present. Due to the paucity of data regarding this pandemic virus together with an unprecedented fast knowledge acquisition worldwide we highlight the importance of this case report of a pre-existing ITP exacerbated by COVID-19.

Because it is an emerging disease, we still do not have sufficient data relating ITP to the new coronavirus.

\section{Conclusions}

Our case suggests COVID-19 as a causal factor of worsening previous ITP, with temporal correlation present and exclusion of other clinical conditions. Further studies are needed on the interaction of the new coronavirus with complications of the hematopoietic system, as in this particular case, thrombocytopenic purpura.

\section{Acknowledgments}

None to declare.

\section{Financial Disclosure}

None to declare.

\section{Conflict of Interest}

None to declare.

\section{Informed Consent}

Not applicable.

\section{Author Contributions}

ML, LMC, JP, SL and AA wrote the article. PB, ZB, ZPF and OB supervised and edited the final version.

\section{Data Availability}

Any inquiries regarding supporting data availability of this study should be directed to the corresponding author.

\section{References}

1. Neunert C, Lim W, Crowther M, Cohen A, Solberg L, Jr., Crowther MA, American Society of H. The American Society of Hematology 2011 evidence-based practice guideline for immune thrombocytopenia. Blood. 2011;117(16):41904207.

2. Cuker A, Cines DB. Immune thrombocytopenia. Hematology Am Soc Hematol Educ Program. 2010;2010:377384.

3. Cines DB, Bussel JB, Liebman HA, Luning Prak ET. The ITP syndrome: pathogenic and clinical diversity. Blood. 2009;113(26):6511-6521.

4. World Health Oganization. Coronavirus disease 2019 (COVID-19) Situation Report-47. 2020. https://www. who.int/docs/default-source/coronaviruse/situationreports/20200307-sitrep-47-covid-19.pdf. Accessed on March 7, 2020.

5. Kaslow RA, Phair JP, Friedman HB, Lyter D, Solomon RE, Dudley J, Polk BF, et al. Infection with the human immunodeficiency virus: clinical manifestations and their relationship to immune deficiency. A report from 
the Multicenter AIDS Cohort Study. Ann Intern Med. 1987;107(4):474-480.

6. Morris L, Distenfeld A, Amorosi E, Karpatkin S. Autoimmune thrombocytopenic purpura in homosexual men. Ann Intern Med. 1982;96(6 Pt 1):714-717.

7. Sloand EM, Klein HG, Banks SM, Vareldzis B, Merritt S, Pierce P. Epidemiology of thrombocytopenia in HIV infection. Eur J Haematol. 1992;48(3):168-172.

8. Cines DB, Liebman H, Stasi R. Pathobiology of secondary immune thrombocytopenia. Semin Hematol. 2009;46(Suppl 2):1 S2-14.

9. World Health Organization. Director-General's remarks at the media briefing on 2019-nCoV on February 112020. https://www.who.int/dg/speeches/detail/who-directorgeneral-s-remarks-at-the-media-briefing-on-2019-ncovon-11-february-2020. Accessed on February 12, 2020.

10. Centers for Disease Control and Prevention. Interim clinical guidance for management of patients with confirmed 2019 novel coronavirus (2019-nCoV) infection, Updated February 12, 2020. https://www.cdc.gov/coronavirus/2019ncov/hcp/clinical-guidance-management-patients.html. Accessed on February 14, 2020.
11. Wang D, Hu B, Hu C, Zhu F, Liu X, Zhang J, Wang B, et al. Clinical characteristics of 138 hospitalized patients with 2019 novel coronavirus-infected pneumonia in Wuhan, China. JAMA. 2020.

12. Huang C, Wang Y, Li X, Ren L, Zhao J, Hu Y, Zhang $\mathrm{L}$, et al. Clinical features of patients infected with 2019 novel coronavirus in Wuhan, China. Lancet. 2020;395(10223):497-506.

13. Chen N, Zhou M, Dong X, Qu J, Gong F, Han Y, Qiu Y, et al. Epidemiological and clinical characteristics of 99 cases of 2019 novel coronavirus pneumonia in Wuhan, China: a descriptive study. Lancet. 2020;395(10223):507-513.

14. Lippi G, Pleobani M, Henry BM. Trombocytopenia is associated with severe coronavirus disease 2019 (COVID-2019) infections: A meta-analysis. Clinica Chimica Acta. 2020

15. Assiri A, Al-Tawfiq JA, Al-Rabeeah AA, Al-Rabiah FA, Al-Hajjar S, Al-Barrak A, Flemban H, et al. Epidemiological, demographic, and clinical characteristics of 47 cases of Middle East respiratory syndrome coronavirus disease from Saudi Arabia: a descriptive study. Lancet Infect Dis. 2013;13(9):752-761. 